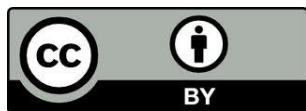

\title{
TÚMULOS E MILAGREIROS: O CASO DA CIGANA SEBINCA CHRISTO
}

\author{
Tombs and Miracle Workers: The Case of the Gipsy Sebinca Christo
}

Lourival Andrade Júnior

Universidade Federal do Rio Grande do Norte - UFRN/CERES.

E-mail: lourivalandradejr@yahoo.com.br

\begin{abstract}
RESUMO: Muitos milagreiros de cemitério estão espalhados pelo território Brasileiro e já fazem parte da vida religiosa de homens e mulheres de todas as categorias e classes sociais. Um dos casos é o da Cigana Sebinca Christo. Morreu e foi enterrada em Lages, município da região serrana de Santa Catarina. O preconceito que ao longo dos séculos se construiu em relação aos ciganos é esquecido pelos devotos de Sebinca Christo, que para melhor se relacionar com a sua milagreira, criam gestos e narrativas para qualificar sua devoção. Os devotos constroem a cigana. Em outro extremo está à família Christo que também a cultua, mas de forma diferente, não aceitando as versões de sua morte trágica descrita na imprensa e nas falas dos não ciganos que nela creem. Em seu túmulo encontramos elementos de diversas práticas da religiosidade, desde velas até bebidas alcoólicas, transformando sua sepultura num mosaico devocional. Sebinca continua viva nas narrativas dos ciganos e dos não ciganos, operando milagres e graças e fazendo com que sua fama continue a se espalhar por diversas regiões do país.

Palavras-chave: Cigana Sebinca Christo; túmulo; devoção; milagre.
\end{abstract}

ABSTRACT: Many cemetery miracle workers are scattered throughout the Brazilian territory and are now part of the religious life of men and women of all social classes and categories. One of these cases is the Gypsy Sebinca Christo. She died and was buried in Lages, which is a municipality in the mountainous region of Santa Catarina. The prejudice which for centuries was constructed towards Gypsies is overlooked by devotees of Sebinca Christo, who to better relate to their miracle worker, create gestures and narratives to describe their devotion. Such devotees construct the said Gypsy. At the other extreme is the family Christo, who also worship her, but in a different way, not accepting the versions of her tragic death described in the press and in the speeches of non-Gypsies who believe in her. In her tomb several elements of religious practices are found renging from candles to alcohol, turning her grave into a devotional mosaic. Sebinca is still alive in the narratives of Gypsies and non-Gypsies, working miracles and graces as well as causing her fame to continue spreading in various regions of the country.

Keywords: Gypsy Sebinca Christo; Tomb; Devotion; Miracle. 
A "santificação" 1 de Sebinca Christo, a cigana, é marcada por duas construções. Uma dos devotos que reinventam a cada momento sua forma de relacionarse com ela, incorporando novos elementos à sua crença e ao seu entendimento individual. $\mathrm{O}$ crente em sua original forma de se ligar ao sagrado busca uma melhor chave para penetrar no mundo dos mortos e com isso conseguir os bens que procura. Os devotos gadjés ${ }^{2}$ construíram a sua Cigana Milagreira. A outra é a devoção que os próprios ciganos têm para com esta cigana, que em vida dedicou-se a prática da quiromancia e a seguir os princípios da ciganidade nômade. $\mathrm{S}$

Vamos diretamente a sua não rápida história.

Sebinca Christo ${ }^{3}$, filha de Thomaz Ivanol e Juliana Christon, grega e de profissão: cigana ${ }^{4}$.

Nessa informação sobre sua profissão no atestado de óbito, aparece o conceito que o escrivão por intermédio dele a sociedade tinha sobre esta mulher que havia falecido. Ao identificá-la como cigana, não pela etnia, mas como sua ocupação, já a coloca no lugar das que não têm território e que são reconhecidas como "ladras, enganadoras, imorais" e todos os adjetivos pejorativos que foram se incorporando aos ciganos ao longo dos séculos. O preconceito à condição cultural cigana é identificado no documento oficial.

Nascida em 1886 (dia e mês são desconhecidos) e falecida em 09 de março de 1965, às 07 horas, em um acampamento cigano na Rua Quintino Bocaiúva, na cidade de Lages no Estado de Santa Catarina, segundo se lê no atestado de óbito.

Já nesses dados, a família ${ }^{5}$ de Sebinca informou que ela não morreu pela manhã e sim no final da tarde, próximo às 19 horas. Isto não é muito relevante, se

\footnotetext{
${ }^{1}$ Trataremos aqui por "santificação" o processo que leva um morto a ser considerado milagreiro e que não passa por nenhuma instância oficial. Ou seja, a "santificação" parte dos devotos, diferente da "canonização" que oficializa a crença.

${ }^{2}$ Gadjé: não cigano.

${ }^{3}$ No atestado de óbito consta o nome: Cefinka Christon, mas os parentes garantem que o nome correto era mesmo Sebinca. Quanto ao sobrenome, foi alterado ao longo dos anos, sendo que vários descendentes de Sebinca escrevem e tem em seus registros várias formas de escrevê-lo, mas todos muito próximos.

${ }^{4}$ Informações contidas em sua Certidão de Óbito.

${ }^{5}$ Entrevistamos no acampamento na cidade de Balneário Barra do Sul (SC) nos dias 27 de dezembro de 2007 e 01 de janeiro de 2008 (o parentesco aqui descrito é em relação à Sebinca): Alexandre Christo (82), nome cigano Boba (filho), Sofia Christo (68), nome cigano Lulugui (nora), Mario Christo (41), nome cigano Mário (neto), Tânia Estevanovich Christo (38), nome cigano Tânia (neta por parte de marido Mário), Pedro Christo (44), nome cigano Dutsa (neto), Tamires Christo (17), nome cigano Dara (bisneta), Alexandre Vitimarcus (19), nome cigano Alexandre (bisneto por parte de esposa - Dara), Petsi Ivanovich Christo (62), nome cigano Petsi (neta por parte de marido falecido), Simone Christo (37), nome cigano
} 
levarmos em conta que os ciganos apenas relatam o que a memória guardou, uma vez que não há nada escrito sobre suas histórias.

A cigana pertencia a um grupo de ciganos nômades, do grupo Rom, que haviam se deslocado da Grécia para o Brasil em 1935.

Segundo Paulo Franklin ${ }^{6}$, muitas pessoas recorriam a Sebinca buscando a cura para alguma doença. Afirma que possuía habilidade em lidar com plantas e fazia remédios para várias moléstias. Segundo ele, as mães levavam seus filhos que recebiam remédios feitos à base de ervas. Caso Sebinca não estivesse no acampamento para entregar no momento, fazia logo depois e enviava para a pessoa que necessitava ${ }^{7}$.

Segundo os jornais e devotos, estava aí mais uma das facetas de Sebinca, que a fazia muito popular e procurada nas vezes que passava por Lages. Ao que se nota, esta procura por Sebinca continuou após sua morte.

Sua morte, conforme óbito assinado pelo Dr. Clito Zapelini $\mathrm{Neto}^{8}$, foi causada por derrame cerebral, hipertensão arterial e arteriosclerose. Segundo Dr. Heron Anderson de Souza (48), Diretor Geral do Hospital Tereza Ramos, provavelmente Dr. Clito já conhecia a paciente, visto ser muito difícil detectar este tipo de óbito apenas com o cadáver, pois requer um conhecimento prévio das doenças do paciente.

A morte de Sebinca em nada se relaciona com morte drástica e dramática como atestam os jornais. No jornal "A Notícia":

"A cigana Sebinca, que já tinha fama na cidade antes de morrer, foi estuprada e torturada em 1965, o que motivou sua morte. Seu túmulo passou a ser bastante visitado, principalmente pelas pessoas mais simples. A história dos milagres que teriam ocorrido se espalhou, atraindo maior atenção." 9

Ainda em outro jornal, “A Notícia”:

Simone (neta por parte de marido - Dutsa). Também entrevistamos Milton Abrão (53) e Vera Christo (32) - (ela bisneta de Sebinca) na cidade de São Leopoldo (RS) em 22 de dezembro de 2007. Este casal já sedentarizado.

6 Paulo Franklin (62). Entrevista realizada no dia 09 de outubro de 2003, em seu escritório de contabilidade, que na época da morte de Sebinca era a funerária onde ele e o pai trabalhavam (Lages/SC) e que foram responsáveis pelo sepultamento.

${ }^{7}$ Esta citação de que a cigana fazia remédios foi relatado por diversas pessoas ao longo da pesquisa, além de aparecer em uma matéria jornalística., mas negada por parentes mais próximos e que conviveram com ela.

8 Dr. Clito era médico muito respeitado em Lages. Envolvido com política e na ajuda dos mais necessitados. Estas informações foram obtidas do Dr. Heron Anderson de Souza (48), Diretor Geral do Hospital e Maternidade Tereza Ramos, em Lages, em entrevista no dia 09 de outubro de 2003.

${ }^{9}$ A Notícia. Joinville (SC), 03 de novembro de 1999. n. 21.411. p. A7. 
"A cigana Sebinca Christo era uma pessoa bastante popular em Lages, nas décadas de 50 e 60. Certo dia, em 1965, Sebinca foi assaltada, torturada, estuprada e assassinada em uma rua da cidade. Enterrada, começou a operar milagres." 10

O trágico aparece como justificador da "santificação", já que não havia em termos de entrega religiosa de Sebinca um motivo que a colocasse como detentora de uma espiritualidade capaz de levá-la à condição de "santa". Não era religiosa, e como os ciganos, não seguia os preceitos católicos na íntegra. Assim, para a imprensa e para os devotos, o sofrimento na morte por meio da dor poderia transformar uma cigana comum em uma "santificada" respeitada.

No jornal local mais importante de Lages, o "Correio Lageano", as notícias sobre a devoção à cigana somente começaram a aparecer com mais freqüência a partir de 2003. Antes disso, há apenas uma notícia no jornal “O Momento", também de Lages. No restante dos meios de comunicação há o silêncio em relação à morte e posterior visitação ao túmulo de Sebinca. Os jornais apenas falavam do túmulo de Frei Silvério Weber ${ }^{11}$.

Esse silêncio que ocorria na imprensa local não é acompanhado pelas pessoas da cidade, que não se cansam de falar de Sebinca e de sua morte trágica. Uns afirmam que ela foi realmente estuprada e assassinada. Outros informam que ela foi assassinada quando foi defender sua filha de um estupro dentro do acampamento. Outros ainda afirmam que ela morreu dentro de sua tenda, que pegou fogo, mas seu corpo mesmo envolto pelas chamas não foi queimado.

Várias histórias. Vários imaginários. Várias significações e sensibilidades.

No atestado de óbito aparece como declarante da morte de Sebinca no cartório de Lages, Wenceslau Franklin da Silva ${ }^{12}$. Entrevistamos seu filho, Paulo

\footnotetext{
${ }^{10}$ A Notícia. Joinville (SC), 03 de novembro de 2000. n. 21.773. p. A6.

11 O único caso de um clérigo que se tornou milagreiro em Lages foi frei Silvério Weber, um dos mais conhecidos religiosos de Santa Catarina, principalmente porque possuía um programa de televisão de exibição estadual, em que todos os dias às dezoito horas (Hora da Ave Maria), rezava com seus fiéis e benzia um copo de água pelas ondas da televisão, que os devotos ou seguravam nas mãos ou colocavam sobre o aparelho de TV. Tinha em Lages um intenso trabalho junto às comunidades carentes e durante muitos anos foi pároco da Igreja do Navio, uma das mais importantes da cidade. Em 04 de março de 2000 faleceu de morte súbita em Lages, a partir daí seu túmulo no cemitério Cruz das Almas começou a receber devotos que pedem por graças, e, observando as placas de ex-votos, são vários os pedidos atendidos.

${ }^{12}$ Dono na única funerária da cidade, Funerária Franklin, que se responsabilizava por tudo relacionado ao óbito. Desde cuidar dos documentos funerários, até limpeza e compra do terreno no cemitério local.
} 
Franklin (62), que afirmou categoricamente que Sebinca era hipertensa, fumava muito e devido sua idade, seu corpo foi se debilitando até sua morte.

"Não tem nada de estupro. A cigana morreu de velha. Eu e meu pai cuidamos de tudo, até da roupa. Pegamos no hospital, embalsamamos, arrumamos no caixão e levamos para o acampamento. Foram três dias de festa. Depois ela foi levada para o cemitério Cruz das Almas e está lá até hoje fazendo milagres. Confio muito nela, já fiz pedido e ela me atendeu." 13

Percebe-se, inicialmente, uma contradição naquilo que aparece no atestado de óbito e na fala do entrevistado, confirmando uma morte natural e não de forma drástica. Já os jornais e as falas de pessoas que cultuam Sebinca informam sua trágica morte. Há necessidade de aprofundar esses fatos policiais, e entender o porquê das contradições. Um dos papéis fundamentais do historiador é pesquisar não somente o que está escrito nos documentos oficiais, mas também quem escreveu e por que o fez desta forma.

Perseguindo os indícios fomos procurar nos arquivos judiciais e hospitalares as pistas do possível crime envolvendo a cigana.

Não há nenhum processo criminal, nem tampouco inquérito policial que se relacione a este suposto crime ocorrido em Lages em 1965. Consultamos 85 processos do ano de 1965, na $1^{\text {a }}$ Vara Criminal. Ainda foram lidos processos de 1964, 1966 e 1967, totalizando mais de 200 processos e nada foi encontrado sobre o suposto crime envolvendo Sebinca Christo. Ainda tivemos a preocupação de ficarmos atentos a nomes parecidos ao da cigana, já que erros ortográficos são comuns quando se trata de nomes e sobrenomes incomuns. Essa busca foi realizada no Depósito Público Judicial da Comarca de Lages em 04 de outubro de 2005, com autorização do Diretor do Fórum, Dr. Luiz Neri Oliveira de Souza.

Também no Hospital Nossa Senhora dos Prazeres, consultamos o livro de internações, e não houve entrada de nenhuma paciente com o nome Sebinca ou parecido. Essa pesquisa foi realizada em 04 de outubro de 2005. Não há livros de óbitos no hospital do ano de 1965, apenas de 1959, 1960 e 1962. Também não há livro de emergência. Segundo Gisele Gonçalves (25) (responsável pelo arquivo morto do hospital), os livros são guardados por 20 anos, principalmente os prontuários, depois são

\footnotetext{
13 Paulo Franklin (62). Entrevista realizada no dia 09 de outubro de 2003, em seu escritório de contabilidade, onde na época era a funerária onde ele e o pai trabalhavam (Lages/SC).
} 
eliminados. Ao conversarmos com as Irmãs Lucina Schacheck (67) e Ernestina Pereira (60), as mais antigas religiosas que trabalham no hospital, elas também informaram que não se lembravam de nenhuma morte trágica envolvendo uma cigana, e caso isso tivesse ocorrido, provavelmente recordariam, já que trabalhavam diretamente com o Dr. Clito Zapelini Neto.

Esse médico, falecido em 1993, era, segundo seu filho, o Dr. Carlos Alberto Zapelini (41): “amigo dos ciganos. Sempre os atendia e era muito ligado. Tinha muitos ciganos na casa deles, o que demonstrava confiança. Meu pai tinha ganhado um medalha de uma cigana famosa, devia ser a Sebinca, que ele nunca deixou de usar" ${ }^{\prime \prime}$.

Os crimes trágicos também apareciam em jornais locais e de circulação estadual. Em 1965 o periódico estadual mais importante era o "Jornal O Estado" que informava as notícias mais importantes de Santa Catarina. Na Coluna "Notícias de Lages" ${ }^{15}$, escrita por Nelson de Castro Brascher, informava os falecimentos na cidade no mês de março de 1965 e não aparece o de Sebinca, nem tampouco a brutalidade relacionada à sua morte, que os jornais, algumas décadas depois, começariam a informar.

O crime não ocorreu. Mas o túmulo de Sebinca passou a ser procurado por devotos de diversas cidades da região e de outros estados. Sua fama como milagreira se espalhou rápido, e hoje as graças realizadas por Sebinca estão nas narrativas de seus devotos.

Forjaram uma morte violenta, qualificando sua força depois de morta. Criaram intimidade em vida, mesmo que isto nunca tenha ocorrido. Deram a ela o "status" de curar gratuitamente pessoas com ervas medicinais. Construíram uma Sebinca que era desejada por eles. Não importava a versão médico-científica, o que valia era o que estava incorporado na devoção. O sentir a cigana passa por agradá-la depois de morta. Presentes são levados e cigarros acesos. Nada mais interessa senão a força que é dada a ela por seus devotos. Sua força está nos fiéis e na sua forma de sempre estar mantendo viva a narrativa da tragédia e de seus poderes curativos. Não esquecendo nunca que era cigana e que possuía já em vida poderes de prever o futuro, pelo menos os gadjés acreditavam nisso, e agora, no mundo do transcendente, seus

${ }^{14}$ Carlos Alberto Zapelini (41). Entrevista realizada em 03 de abril de 2005, em Lages/SC.

${ }^{15}$ O Estado. Florianópolis (SC), 09 de abril de 1965. P. 6. 
poderes se ampliaram já que a morte a colocou num lugar que os vivos não conseguem enxergar.

Sobre a versão dos devotos e da imprensa que destacam o sofrimento porque passou Sebinca ao morrer, pode ser analisada como mais uma transposição de fatos ocorridos com outra pessoa e que se incorporaram à cigana. Uma hipótese que levantamos é a mistura de histórias. No mesmo ano da morte de Sebinca, também morreu em Lages a menina Salete de Fátima Madruga. Esta realmente foi assassinada e estuprada. O crime ocorreu em setembro, ou seja, seis meses após a morte de Sebinca. O corpo de Salete está enterrado no Cemitério de Nossa Senhora da Penha, distante de onde está sepultada a cigana. As duas têm em comum o processo de "santificação". São milagreiras e reconhecidas pelos devotos como detentoras de diversos poderes. Para eles, umas das questões que as aproximam é a morte, vista como trágica nos dois casos. Sabemos que Sebinca não morreu nas condições descritas pelo devocionário popular, mas, com o passar dos anos, essas histórias e narrativas foram se cruzando, justapondose, mesclando-se e, nos apropriando do universo cigano, se embaralhando. Hoje a "história" da morte de Sebinca é a história da morte de Salete de Fátima Madruga.

A segunda construção se dá por meio das falas da família Christo. Estes ciganos que conviveram com ela, depositam em sua alma uma enorme devoção. Afirmam que seus poderes se fizeram após a morte, já que para eles, em vida, era igual a qualquer outra cigana. Não teve morte violenta. Não manipulava ervas para fazer remédios. Nunca havia estado em Lages, sendo assim, não teve contato com os moradores da cidade. Apenas vivia como cigana nômade e lia a sorte para ganhar dinheiro.

Ao que parece, os ciganos acabaram incorporando a devoção à Sebinca, quando devotos gadjés começaram a descrever suas graças. Ciganos levam presentes aos seus mortos, independente de quem seja o sepultado. Pedro Cristo (47), neto de Sebinca, nos informou que sempre leva doces para as crianças que estão no túmulo com sua avó. Ao perguntarmos a Boba $^{16}$ (82) e Sofia Cristo ${ }^{17}$ (68), sobre esta forma de homenagear os seus mortos, Boba afirma:

\footnotetext{
16 Boba é o nome cigano de Alexandre Christo, filho de Sebinca, Faleceu em 24 de maio de 2008 na cidade de Araucária (PR), onde estavam acampados.

17 Sofia Christo esposa de Alexandre Christo e nora de Sebinca. Estava com ela no momento de sua morte. Sofia Christo, chamada pelos ciganos de Lulugui, faleceu no dia 17 de agosto de 2009 na cidade de Irati (PR).
} 
"Levamos presentes sim, mais bebida... aquilo que gostava quando tava vivo. Abrimos a garrafa e jogamos um pouco encima e depois em volta do túmulo, depois o que sobrar colocamos encima para ela beber mais. Pra minha mãe levo vinho, ela gostava de vinho." 18

Os gadjés de Lages, ao longo dos anos, foram observando presentes entregues em seu túmulo, provavelmente levados pelos parentes de Sebinca, e com isso começaram a reproduzir esta prática. Aos poucos isto foi se ampliando e novas incorporações foram anexadas ao culto de sua alma. É fundamental entendermos que na religiosidade não oficial a flexibilidade é enorme, já que não existem regras definidas nem rituais fechados. Cada devoto se relaciona com seu "santificado" da forma que lhe é mais conveniente e onde sua fé pode ter mais força e reciprocidade.

Os ciganos, ao levarem presentes aos seus mortos, pelo menos entre os Christo é uma prática, possibilitaram que as pessoas que visitavam o Cemitério Cruz das Almas e sendo até mais específico, o túmulo dos milagreiros, observaram esses presentes e os consideraram como oferendas. Daí o possível início da devoção. Vale ressaltar que o túmulo de Sebinca fica muito próximo ao "dos Canozzi"19, onde a "santificação" se iniciou pelo menos uns sessenta anos antes da morte da cigana.

Lages é um local onde há uma íntima ligação entre o sagrado e o mundo dos vivos, assim as devoções se tornaram plausíveis. Desde as histórias contadas por tropeiros e as lendas que se espalharam pela região, muitos devotos encontraram nestas narrativas uma forma direta de relação com o sobrenatural. Com o tempo estas narrativas foram se misturando e a consolidação das "santificações" se tornaram mais fortes. Inclusive da cigana Sebinca Christo. Sua família percebeu que esta devoção se tornava mais presente em Lages e aos poucos foi incorporando esta prática, e seus poderes milagrosos se espalharam também entre os ciganos de outros grupos. Dos ciganos aos devotos. Dos devotos aos ciganos.

Duas construções que acabam se encontrando na crença nos poderes da cigana. Uma não desqualifica a outra. Aparentemente se contrapõem, mas de forma mais exata acabam se justificando e se justapondo. Ciganos e gadjés têm em Sebinca

\footnotetext{
18 Alexandre Christo. Entrevista realizada em 27 de dezembro de 2007 no Balneário Barra do Sul/SC.

19 "Irmãos Canozzi", segundo o termo popularmente conhecido na cidade, na verdade não se tratava de dois irmãos, mas de patrão e empregado, Ernesto Canozzi e Olintho Pinto Centeno, que foram assassinados por dois irmãos, Thomaz e Domingos Brocato no dia 01 de maio de 1902.
} 
um elo bastante presente de relação. Em vida, como é comum entre os ciganos e a sociedade que os rodeia, a cigana deve ter recebido os olhares de preconceito e estranhamento que ao longo da história dos ciganos ocorreu. Depois de morta, os gadjés acabaram se curvando aos poderes milagrosos desta cigana.

Este é mais um fato original na devoção a Sebinca Christo. As falas da família contradizem as narrativas dos devotos. Da mesma forma, os devotos ignoram a versão familiar e a científica. Nos "santificados" espalhados pelo Brasil, as narrativas dos devotos e familiares acabam se reforçando. A mesma cigana é construída como "santificada" por dois olhares distintos, isto faz ampliar o seu rol de devotos e os agrados feitos a ela. Sebinca não é mais só dos ciganos, ela é também dos gadjés e viceversa. Inclusive, são estes últimos, que por força de não estarem ligados a nenhuma tradição de conceitos fixos, inauguram, a cada novo pedido e a cada nova oferenda, a sua forma original de cultuá-la. Como cigana, não seguiu os padrões esperados pela sociedade sedentária, depois de morta foi construída como milagrosa por visões distintas. É uma "milagreira de cemitério" de duas culturas, de duas tradições, de duas construções.

Da mesma forma que o conceito aqui empregado de "santificação" referese à forma que os devotos tem de qualificar um morto comum e transformá-lo em especial, contrapondo-se a visão de "canonização" estabelecida pelos cânones católicos, o termo "milagreiro ou milagreira de cemitério" se refere aos mortos dotados de poderes, instituídos pelos devotos, e que resolvem problemas materiais e espirituais dos que os procuram. Este conceito de "milagreiro de cemitério" busca uma melhor identificação destas personagens no campo devocional e se contrapõe ao termo "santo ou santa de cemitério" por acreditarmos que este último utiliza um termo (santo ou santa) que já está amalgamado nos discursos oficiais católicos. Ou seja, para ser santo ou santa é preciso seguir os passos estabelecidos pelas leis da Santa Sé: Venerável, Beato e Santo. Já o "milagreiro ou milagreira" dependem única e exclusivamente dos devotos para assim serem reconhecidos e seus poderes justificados. A relação de pertencimento entre o milagreiro e seu devoto é expresso em sua dedicação em divulgar seus poderes e demarcar o território devocional de forma a não deixar dúvidas de seus poderes: o túmulo se torna o altar não oficial da devoção e da demonstração dos agradecimentos. 
Ao longo de nossa pesquisa do campo devocional brasileiro, já catalogamos noventa e cinco milagreiros e milagreiras em diversos estados. Ainda continuamos na busca. Mas, o que nos parece mais recorrente são as formas de morte que justificam estas devoções. O trágico é sem dúvida o que melhor qualifica o morto e seus poderes. O trágico pode estar ligado a: assassinato a tiros (João Baracho em Natal/RN), suicídio (Jandira em Campinas/SP), espancamento (José Leão em Florânia/RN), degola (Maria Bueno em Curitiba/PR), linchamento (Antero da Costa Carvalho em Catalão/GO), atropelamento (Menina da Cruz em Jardim do Seridó/RN), estupro seguido de morte (Salete de Fátima Madruga em Lages/SC). Aqui apenas alguns exemplos do trágico como o qualificador do poder que será instituído ao morto. Vale ressaltar que estas mortes, de alguma forma, tem o poder de apagar o que o morto fazia em vida. Assassinos, cangaceiros, prostitutas e outros agentes sociais, que por suas práticas são marginalizados em vida, passam a operar milagres após sua morte trágica. $\mathrm{O}$ trágico purga os pecados da vida. Além disso, o morto agora tem a oportunidade de pagar por meio de milagres e graças pelos erros que cometeu.

Ainda outro tipo de morte serve para qualificar o morto. São as mortes por doença. Neste caso, é necessário que o morto tenha tido uma vida de dedicação ao cristianismo para depois de morto ser cultuado. No caso das crianças, a morte por doença é ainda mais qualificadora. Temos relatos de várias crianças que morreram por diversos males, sofreram, e se tornaram poderosos milagreiros no campo devocional não oficial. Sua pureza é ainda mais destacada e potencializa seus poderes. Podemos citar, entre tantos casos: Antonio da Rocha Marmo em São Paulo/SP e Vitória Salete Nunes em Chapecó/SC.

Também religiosos (padres, freis e freiras) tem se tornado milagreiros importantes em diversas partes do Brasil. A Igreja oficial não os reconhece como "santos", mas os devotos os cultuam como "milagreiros". Neste caso, a morte não precisa ser necessariamente trágica, mas o morto clérigo, na esmagadora maioria dos casos, já era visto como homem bom e dedicado aos pobres e necessitados durante sua vida religiosa. Aqui citamos, entre muitos: Frei Silvério Weber em Lages/SC e Padre Pelágio Sauter em Goiânia/GO.

Nos casos apresentados acima, ainda teríamos que incluir outras formas de morte que também enquadram o morto na categoria de milagreiro, mas estamos 
convencidos que, as mortes trágicas são as que merecem mais destaque. O martírio, a tortura, a incompreensão que leva o ser humano a perder a vida, de alguma forma gera uma piedade no devoto que o faz ver neste morto um dos "seus". O morto está perto, conhece seus dilemas e suas vontades. Normalmente os devotos destes milagreiros vivem nos locais onde eles anteriormente viviam. Ou seja, eles conhecem os lugares e as pessoas destes espaços. O devoto vê o sofrimento como parte da constituição da sacralidade que dotará o morto de poderes. O martírio cristão se resignifica.

Sebinca Christo não morreu de morte trágica. Viveu e morreu como cigana. Mas, o trágico está nas narrativas de seus devotos, que são muitos, e que acreditam que seus poderes estão nesta morte "desejada" e nos seus conhecimentos como cigana que foi. Isto reforça ainda mais o trágico como o qualificador. A cigana teve a morte que os devotos inventaram para ela. Tragédia e ciganidade como compósitos de uma devoção que não para de crescer.

A barraca sempre foi o local seguro e identitário de Sebinca Christo e de todos os ciganos nômades. Depois de sua morte e sua "santificação", o túmulo passou a ocupar esse espaço onde ela não deixou de ser cigana e passou, segundo a construção de seus devotos, a utilizar de seus poderes para ajudar aos que necessitavam.

$\mathrm{Na}$ construção dos devotos gadjés, ainda na barraca, a cigana era dotada de poderes, tanto sobrenaturais (ler a sorte) quanto curativos (fazendo remédios por meio de ervas medicinais). Para eles, no túmulo, continuou desempenhando o papel de ajudar a todos que pedem a ela, independente de quem seja. A "santificada" não promove exclusões, diferente do que viveu seu povo ao longo da história.

Sebinca é, para os gadjés, a cigana que agrega todos os conhecimentos adquiridos pelo seu povo ao longo dos séculos. Por isso seus poderes se ampliaram após a morte.

A morte de Sebinca, independente da versão, se deu na barraca, nômade, e dali seu corpo foi para um túmulo, ou seja, sedentário. Da barraca ao túmulo, lugares onde se consolidaram as construções de sua "santificação".

Esse culto se modifica e se reforça, como pode se observar, acompanhando o túmulo ao longo dos anos. Inicialmente velas brancas, flores e cigarros ${ }^{20}$. Depois cidras, vinhos, cerveja e água. Mais à frente no tempo: frutas, bijuterias, baralho,

${ }^{20}$ É com os cigarros que os devotos fazem pedidos. Normalmente acendem e dão alguns tragos, depois depositam sobre o túmulo ou ao lado dele. 
batons $^{21}$. Seguindo, mais velas, aparecendo além das brancas, também vermelhas, corde-rosa, amarelas, roxas e pretas. É por meio dessas oferendas que pudemos perceber como o culto a ela foi se resignificando e se recriando a cada devoto que buscava por seus poderes. Os ciganos continuaram levando apenas aquilo que Sebinca gostava como vinho e embutidos, além de velas brancas e flores.

Em relação aos pedidos feitos à cigana, vamos destacar alguns recolhidos de 2002 a 2012: "Cigana eu peço ajuda para eu voltar para o meu serviço"; "Peço que meu filho pare de beber e viva com a mulher dele Obrigada"; "Peço que o Luiz me ajude e volte para casa que ele largue das outras mulheres e só pense em mim. Que o Luiz me dê muito dinheiro e me ame e só pense em mim peço para se resolver meus problemas na justiça"; "Peço que nós ganhamos o $1^{\circ}$ lugar no festival"; "Eu quero passar de ano"; "Me ajude no colégio"; "Me ajude a arrumar um emprego"; "Anderson te amo"; "Agradeço por tudo de bom que vem acontecendo na minha vida"; "Sebinca porque você não me atendeu eu ainda estou esperando a minha ajuda tá bom confio em você me ajuda a conseguir o que eu quero obrigado ???".

Como se percebe, a cigana é chamada para resolver problemas dos mais variados, desde relacionamentos até emprego e questões escolares. Também os devotos se sentem tão íntimos da milagreira que cobram por uma resolução rápida de seus pedidos.

Em muitos momentos da entrevista com os Christo ficou evidente que todos são devotos de Sebinca, mas se definem como católicos. Boba, de forma clara, afirma: "Ela era católica, nós somos Católicos Apostólicos Romanos. ${ }^{22}$ ",

Não há sentimento de pertencimento em relação ao Brasil, mas há uma aproximação com a maioria dos brasileiros no que tange à religião. Ser católico é estar mais próximo da sociedade sedentária que crê. Não são praticantes, ou seja, não adquiriram o hábito de ir a missa aos domingos, comungar, confessar e utilizar as demais práticas católicas, mas não deixam de reafirmar incisivamente seu catolicismo não praticante. Acreditam nos santos, especialmente em Nossa Senhora Aparecida, mas não se esquecem de Santa Sara Kali, protetora dos ciganos e que tem como aproximação imediata a padroeira do Brasil à cor da pele. As duas são negras.

\footnotetext{
${ }^{21}$ Com os batons os devotos escrevem sobre o túmulo seus pedidos e também os agradecimentos.

${ }^{22}$ Alexandre Christo. Entrevista realizada em 27 de dezembro de 2007 no Balneário Barra do Sul/SC.
} 
São católicos sem serem reconhecidos como tal. São diferentes ao olhar dos praticantes, porque são ciganos. Seguir seu caminho como ciganos nômades e católicos, de alguma forma, ameniza os problemas. Pelos menos eles acreditam nisso.

Ao perguntarmos o porquê de Sebinca Christo ter se tornado uma "milagreira" para milhares de devotos, ciganos e não ciganos, a resposta é emblemática: "E agora... é o que nós também queríamos saber!" 23

Surpreendem-se com a dimensão que tomou o culto a Sebinca, mas reforçam seus poderes, mesmo não concordando com as práticas de seus devotos junto ao seu túmulo, tampouco quanto às narrativas que descrevem uma morte trágica para ela. Para os Christo, é bom ter uma cigana que é aceita pelos gadjés. Esta cigana depois de morta não está mais pautada pelo preconceito que em vida deve ter sentido. Além dos Christo, para todos os ciganos é de suma importância ter uma dos seus sendo aceita pelo mundo sedentário e não cigano. Sebinca dá um ar de dignidade aos ciganos e mostra que também um deles pode ajudar e fazer parte da vida cotidiana dos gadjés sem causar estranhamentos. Sebinca introduz o mundo romani (dos ciganos "rom") nas casas e orações dos não ciganos. A religiosidade não oficial referendou, por intermédio dos devotos, os poderes milagrosos da cigana que se tornou aceita e respeitada também pelos gadjés. Sua morte e "santificação" fizeram superar o preconceito.

Até mesmo o olhar de estranhamento que sempre acompanhou os romani, por sua tradição nômade, foi de alguma forma superada pelos devotos de Sebinca. Para eles, a cigana possuía uma enorme relação com a cidade de Lages, tinha estado lá por diversas vezes, e já era esperada pelos moradores, pois sabiam que sempre retornaria, segundo os relatos, para o mesmo local de acampamento, perto do Mercado Municipal, no centro da cidade. Para os familiares de Sebinca, isto não ocorreu. Sebinca Christo nunca havia estado em Lages antes. Mas, o que é relevante para a religiosidade não oficial, são as diversas possibilidades que se abrem quando da devoção. O importante para os devotos era tê-la como uma moradora, ou no mínimo, conhecedora do lugar, Lages, e pelas diversas construções e narrativas, passou a ser.

Os ciganos sempre têm notícias uns dos outros. Sedentários e nômades não perdem seu contato. Os Christo possuem ainda mais um elemento que os une como família: Sebinca Christo. A cigana que se tornou milagrosa e foi "santificada" pelo

23 Alexandre e Sofia Christo.. Entrevista realizada em 27 de dezembro de 2007 no Balneário Barra do $\mathrm{Sul} / \mathrm{SC}$. 
devocionário da religiosidade não oficial é um elo importante entre seus parentes. Ela depois de morta uniu mais a família do que fazia, provavelmente, em vida. Seu poder unificador não está apenas relacionado aos pedidos deixados por seus devotos em seu túmulo, ela também une ciganos da família que vivem em cidades e estados diferentes, os sedentários, bem como os nômades que continuam seguindo seus passos na ciganidade. Sebinca une iguais e diferentes.

Sebinca Christo conseguiu depois de morta juntar em torno de si devotos que ultrapassam as barreiras dos preconceitos, ou sequer se dão conta deles. Cigana, nômade, mulher, leitora de sorte, de um grupo que vendia tachos, católica, fumante de cachimbo $^{24}$, apreciadora de vinhos e embutidos. Tudo isso compõe a cigana que se tornou milagrosa e que atrai centenas e até milhares de devotos todos os anos ao seu túmulo no Cemitério Cruz das Almas em Lages, cidade da região do planalto serrano de Santa Catarina.

Vale ressaltar que essa devoção não se iniciou e cresceu em qualquer lugar. Foi em Lages. Cidade onde a modernidade até hoje teima em não tomar as ruas e as casas, onde as narrativas se sobrepõem aos fatos e onde o religioso está impregnado na maioria dos moradores, que foram juntando um pouco de cada fala, história, lenda e mito, possibilitando um enorme emaranhado de devoções. Lages não é um lugar qualquer.

Sebinca já não é mais uma simples cigana, ela é a construção de inúmeras lembranças e memórias. O que ela foi e fez em vida já não importa para seus devotos. Ela é de todos, ciganos e não ciganos, que de forma distinta inventaram esta cigana milagrosa. Seus poderes se ampliaram com o crescimento de seus devotos.

É assim, o poder do "santificado" está diretamente ligado à quantidade de seus devotos, que ao longo do tempo vão recriando narrativas e construindo novos olhares e habilidades para a sua divindade. Dois olhares e duas construções, uma só cigana. Nessas construções, de um lado os devotos gadjés e a imprensa, de outro a família, tendo uns convivido com ela e outros que se alimentaram das narrativas dos mais velhos. O ontem se perde e o presente se recria a cada devoto que vai até seu túmulo. Os ciganos continuam peregrinando, mas possuem, pelo menos os nômades, um lugar fixo de encontro e de devoção: a sepultura de Sebinca Christo.

${ }^{24}$ Segundo os parentes de Sebinca ela fumava cachimbo e nunca cigarro. 
Tânia Christo relata: "O nome da Sebinca corre entre todos os ciganos, parece que ela está viva. ${ }^{25}$,

A morte sedentarizou os seus restos mortais. Mas Sebinca continua a caminhar com seus parentes, nunca deixou de ser cigana. E, segundo eles, nunca deixou de ajudá-los, protegendo-os de acidentes na estrada em suas viagens. Sua família nômade continua mantendo as tradições ciganas, não só religiosas, mas também em relação à sua ciganidade.

A família Christo segue seu caminhar levando consigo as memórias de sua cigana milagrosa, que agora é de todos os "brasileiros" ${ }^{26 "}$ também. Como dizem seus devotos: "uma cigana milagreira" ou "uma milagreira cigana".

Recebido: $16 / 02 / 2012$

Received: 02/16/2011

Aprovado: $02 / 07 / 2012$

Approved: 07/02/2012

\footnotetext{
${ }^{25}$ Tânia Christo (neta de Sebinca por parte de marido - Mário). Entrevista realizada em 27 de dezembro de 2007 no Balneário Barra do Sul/SC.

26 "Brasileiros" foi o termo utilizado pelos ciganos entrevistados para se referirem aos não ciganos. Outro termo que é comumente utilizado é "gadjé"
} 